\title{
DE MAURY ATÉ COIMBRA COM UMA ESCALA ${ }^{1}$
}

\section{FROM MAURY TO COIMBRA WITH ONE STOPOVER}

\author{
Elias Coimbra da Silva \\ Mestre - Universidade Federal da Grande Dourados \\ coimbraelias@hotmail.com
}

\begin{abstract}
RESUMO: Neste texto, fruto de discussões e reflexões empreendidas no âmbito de nossa pesquisa ainda inconclusa, a proposta é comparar a trajetória de vida de dois sujeitos, separados no espaço e, sobretudo no tempo, a partir daquilo que atualmente se tem denominado como micro-análise; atentando sempre para o caráter meramente instrumental dessa delicada transposição, para não incorrermos em anacronismo. Para tanto, primeiramente discorreremos com brevidade sobre o conceito de escala, do qual resulta o olhar micro-analítico, além de abordarmos sua utilização pelo geógrafo, pelo antropólogo e pelo sociólogo até chegarmos ao pesquisador que nos importa: o historiador. Na sequência faremos uso da análise micro-escalar para compreendermos a realidade nuançada das trajetórias de Pierre Maury, que viveu nos Pireneus do século XIII; e de José Coimbra, que viveu no interior de São Paulo no século XX; concluindo, enfim, com uma comparação reveladora entre as duas biografias que, tão distantes no tempo, guardam pontos de contatos quando olhadas a luz da longa duração.
\end{abstract}

PALAVRAS-CHAVE: Escala. Micro-história. Contexto.

ABSTRACT: In this paper that results of discussions and reflections undertaken within our research still unfinished, the proposal is to compare two life courses that is separated in space but especially in time, from what is called today: microanalysis, always paying attention to the character merely instrumental of this delicate transposition for not incur anachronism. To do so, first we will discuss briefly about the concept of scale from which the microanalytical view emerges and after we will discuss its use by the geographer, by anthropologist and sociologist until we get to the researcher who matter us: the historian. Following the analysis we will use micro scale to understand the nuanced reality of the trajectory of Pierre Maury, who lived in the Pyrenees of the thirteenth century, and of the trajectory of José Coimbra, who lived in São Paulo in the twentieth century; concluding finally with a revealing comparison between the biographies of two subjects that (so distant in time) keep contact points when they are thought on the long duration.

KEYWORDS: Scale. Microhistory. Context.

\footnotetext{
${ }^{1}$ O termo Escala, aqui, ambiguamente utilizado ora como 1) “parada"; ora como 2) stricto sensu, uma metodologia de enfoque (ou aporte).
}

Oficina do Historiador, Porto Alegre, EDIPUCRS, v. 7, n. 1, jan./jun. 2014, p. 121-137. 


\section{As partes são mais do que sua soma}

Oriundo que sou de uma outra "província" do conhecimento - ainda que da mesma "humanidade" -, creio ser útil indicar, brevemente, algumas circunstâncias que envolvem o conceito de Escala, indicação essa, de caráter propedêutico; e só depois abordar a questão principal.

A Geografia (já) nasceu sob a influência da noção de recorte da realidade. A “Geografia Científica" é herdeira da Ilustração (Aufklärung) e irmã (bastarda?) do Romantismo. Ela apenas engatinhava quando os europeus assistiram à chamada "Primavera dos Povos" - posto que a obra máxima de Alexander Von Humboldt ${ }^{2}$, "Kosmos", começou a ser publicada em 1845. No mesmo século XIX, a condição de "ciência regional" - denominação hoje freqüente, nos países anglosaxônicos, de uma certa geografia economicista ou economia geográfica - impõe, desse modo, à Geografia, essa noção de recorte: intrínseco ao atual conceito de Escala. Tal "condição regional”, fruto do pensamento de La Blache, emergiu no bojo das disputas ideológicas entre esse francês e o alemão Ratzel - o pai do Determinismo Ambiental - que, por sua vez, advogava a premência de uma "Geografia Geral".

A região, nesta forma de compreensão [a forma de La Blache], é o locus da coexistência de formas de vidas vegetais e animais numa combinação harmônica e singular. Sendo esta harmonia considerada pelo resultado direto das imbricações dos diversos elementos vivos ali interagentes, inclusive o homem. Esta combinação histórica toma a região como um organismo vivo e completo, caracterizada por uma combinação ímpar e, conseqüentemente, autóctone, distinta e separável das demais. (RIBEIRO; GONÇALVEZ, 2001, p. 86)

A guerra irresoluta entre "regionalistas" (com o perdão do termo) e "generalistas", obliquamente produziu a tese de que uma realidade em pequena Escala se desfaz quando observada a partir de uma Escala maior. Um exemplo: as pessoas que moram em Ponta Porã/BR e Pedro J. Caballero/PY têm uma percepção de fluxo constante dentro do conjunto de geminação urbana, enquanto que na escala Nacional, os administradores (por exemplo) de uma região lidam

\footnotetext{
${ }^{2}$ Apontado como o "pai" dessa "Geografia Científica" (as aspas estão aqui postas para relativizar a paternidade de um e a cientificidade da outra).

Oficina do Historiador, Porto Alegre, EDIPUCRS, v. 7, n. 1, jan./jun. 2014, p. 121-137. 
com orçamentos e planejamentos não geminados - ou melhor, lidam com questões divididas, divididas pela fronteira.

Essa não é uma definição muito distante daquela operada na historiografia das últimas décadas. Sem que tal circunstância nos conduza a estabelecer uma relação de causalidade, pois, aparentemente, o historiador se nutriu de outro solo. De qualquer forma, a Escala, na concepção do aporte da Micro-História, individualiza a porção de realidade (o recorte) estudada, explicando assim seu sentido, como alguma coisa imanente. Ao contrário na História Local (evito dizer também "Regional", para não causar uma confusão com a Geografia), uma vez transcendente, o sentido deve ser continuamente emprestado da Escala ampliada - aquilo que, por herança da Cartografia, pode ser denominado "Pequena Escala",

A História Local, nesse sentido, é meramente um apêndice da História Geral, apêndice cuja única razão de ser encontra-se na resolução de um problema de ordem prática: o chamado recorte de pesquisa - recorte esse, aliás, muitas vezes condicionado por questões as mais arbitrárias, como, por exemplo, a divisão de competências acadêmicas (e, portanto, de financiamento de pesquisa) no nível político-administrativo. Assim:

Uma prova evidente disso pode ser encontrada na forma como foram concebidas as grandes obras de síntese [...]. Para citar apenas um exemplo, a História econômica e social da França, coleção reunindo vários volumes dirigida nos anos 1960-1970 pelos dois maiores historiadores cujos nomes podem servir de emblema àquele momento da pesquisa: Ernest Labrousse e Fernand Braudel, é baseada na integração de centenas de monografias de todos os tamanhos, sem que em nenhum momento tenha sido realmente colocado o problema de saber se os dados coletados no nível local guardavam significação constante quando reutilizados em quadros mais amplos [...]. (REVEL, 2010, p. 437)

Escrever sobre o Local, nesse exemplo das monografias - os "estudos de caso" obumbra-se frente ao poder explicativo da História Nacional. Estranhamente a ideia de nação -

\footnotetext{
${ }^{3}$ Mantenho a acepção geográfica de pequena Escala e grande Escala, primeiramente por me parecer mais lógica do que a historiográfica, mas também, principalmente, para incrementar o diálogo teórico entre história e geografia. Assim, a "pequena escala" é aquele olhar macro e simplificador que, enxergando de longe, consegue abranger uma área maior: a país, o continente etc. Ao passo que a "grande escala" é o olhar detalhado que, ao se aproximar deveras do objeto, não consegue ver o conjunto onde ele se insere. Disso decorre que, em Geografia, a Escala é um atributo do sujeito e não, como na Micro-História, do objeto.
}

Oficina do Historiador, Porto Alegre, EDIPUCRS, v. 7, n. 1, jan./jun. 2014, p. 121-137. 
ou ideologia - surge como anteparo desse poder explicativo que, como apontou Revel, costura-se com fragmentos de fatos: um poder político ${ }^{4}$, portanto, mais do que "explicativo".

O aporte da perspectiva da Micro-História - assim como daquilo a que me referi como "recorte" - seria então, usando uma expressão consagrada: idiográfico ${ }^{5}$. Em ambos os casos, o pesquisador mantêm diante dos olhos, um determinado fenômeno particular. Porém, as semelhanças tencionam-se nesse ponto. Pois, é um pouco diversa a utilização que cada uma das perspectivas teórico-metodológicas faz dos estudos em "Grande Escala”. A propósito, em última análise, poderíamos chamá-la de "escala do corpo humano" - na terminologia de Lencioni : essa Escala “[...] relativa ao lugar que o corpo individual ocupa. Essa dimensão topográfica mas ausente na discussão sobre a cidade". (2008, p. 18).

O essencial, na Micro-história, não se esgota com a ampliação da Escala. Não obstante as diferenças metodológicas resultantes da dispersão dessa "escola" - fato que, secundariamente, impediu a formulação de um programa comum; além do (fato) principal: uma ética antiabstracionista, que justamente é contrária a "programas comuns" -, a Micro-história nasceu "como uma reação frente a um certo estado da história social" (REVEL, 1998, p. 16). Foi, portanto, uma reação, ou melhor, uma proposta crítica. Crítica essa, mormente, possibilitada pelo contato com outra área do saber - nesse caso a Antropologia - e cujo objetivo primordial, mais do que conhecer de perto as realidades cotidianas desta ou daquela localidade, para demonstrar a ubiquidade de "leis gerais", era "fazer aparecerem, por trás da tendência geral mais visível, as estratégias sociais desenvolvidas pelos diferentes atores em função de sua posição e de seus recursos respectivos [...]”. (Ibidem, p. 22)

Deste modo, a própria noção de Contexto - basilar na História Social - sofre uma transformação; transformação inclusive, proporcional à Escala. Esse gesto "transformador" que corresponde ao "ver de perto" da Micro-análise - ou utilizar o microscópio ao invés do

\footnotetext{
${ }^{4}$ Não estou dizendo - é obvio - que Labrousse e Braudel estariam fundando a "ideologia do nacionalismo" na década de 1960. Hobsbawm (2003) aponta o séc. XIX como o terminus a quo, desse discurso. Entretanto, o uso do discurso não deveria ser improvável, nesse caso; sejam quais fossem as suas finalidades.

${ }^{5}$ Refiro-me à dualidade já muito discutida nas Humanidades (veja-se Windelband em seu "Geschichte und Naturwissenschaft"), segundo a qual elas, Ciências Humanas, seriam nomotéticas ou seriam idiográficas. Dito de outro modo, elas pesquisariam as regularidades do conjunto dos fenômenos que estudam, ou então elas escreveriam teses ad hoc sobre cada fenômeno particular.
}

Oficina do Historiador, Porto Alegre, EDIPUCRS, v. 7, n. 1, jan./jun. 2014, p. 121-137. 
telescópio, para usar uma expressão de Hobsbawm ${ }^{6}$ - quando dirigido à prática de contextualizar, permite situar os sujeitos num plano (qualitativamente) diferente do habitual. Não mais as contingências da Classe, das Instituições, da Moral, da Cultura (stricto sensu) etc, mas as negociações vis-à-vis, entre os próprios sujeitos: a “objetivação participante" (que é a constituição dos acontecimentos por interação) no interior daquilo que, nas Ciências Sociais, se tem denominado "Campo".

Ora, se a influência da Antropologia - ou "duma determinada Antropologia" - foi o veículo de transformação que permitiu ao historiador ver melhor (porque via de perto), os tons dessa "nitidez ocular" eram fruto, igualmente, daquela "semi-ótica"7 epistemológica que os pesquisadores dessa mesma ciência chamam de Gesto Etnográfico ${ }^{8}$ : esse “[...] movimento tanto físico quanto intelectual que leva o cientista a descontextualizar-se socialmente para poder recontextualizar-se no 'terreno"” (CABRAL, 2007, p.191). Fez-se, nesse sentido, necessário ao historiador conhecer "por dentro" os grupos que estudava para entender, não simplesmente o que eles fazem quando vivem ordinariamente suas vidas, mas, sobretudo: “[...] que diabos eles acham que estão fazendo". (GEERTZ, 1998, p. 89)

Ver de perto - como esse "movimento físico" da referência de Pina Cabral - nem sempre seria possível. Para ser mais preciso, raramente o historiador tem a oportunidade de se locomover de seu habitat e realizar o célebre "trabalho de campo" etnográfico. Então, como ele pode proceder? De fato, nem mesmo os antropólogos acreditam cegamente na Empatia (Einfühlen) como conditio sine qua non de uma Verstehen (compreensão) rigorosamente válida. Desde, pelo menos, a publicação do livro: "Um diário no sentido estrito do termo", em 1967, por decisão da viúva de Bronislaw Malinowski (1884-1942), texto no qual há comentários - digamos, no mínimo: não "politicamente corretos" - do autor sobre as populações que ele estudou, enfim, desde pelo menos essa polêmica, os antropólogos têm se concentrado em re-definir o estatuto de suas metodologias.

\footnotetext{
6 "Eric Hobsbawm chegou a usar a imagem de um microscópio e de um telescópio, para distinguir a abordagem micro-histórica da macro-histórica, enfatizando que é uma questão de escolha da técnica apropriada". (BATALHA, 2009, p. 176)

${ }^{7}$ Esse é um trocadilho entre o conceito de semiótica, enquanto linguagem, e a ambigüidade do ato de "olhar" (olhar ou ver, ou enxergar, ou entender etc.).

${ }^{8}$ A utilização desse conceito fez-se necessária para evitarmos aquele termo mais clássico: "observação participante"; proscrito por seu matiz ideológico.
}

Oficina do Historiador, Porto Alegre, EDIPUCRS, v. 7, n. 1, jan./jun. 2014, p. 121-137. 
O resultado dessa celeuma toda pode ser comemorado pelos historiadores. A partir de então, os antropólogos começaram a formular novas propostas e, só para citar um exemplo, chegou-se ao entendimento (entre outras coisas) de que melhor do que entrar na pele de uma pessoa - para entender profundamente seu Modo de Vida - seria mais produtivo interpretar em termos de nossa própria cultura os significados da cultura dessa (outra) pessoa (GEERTZ, 1998). Pois, o Antropólogo escreve um texto "culturalmente científico" sobre a cultura alheia e esse texto se dirige às pessoas de "sua própria" sociedade; de forma que o sentido último daquele Modo de Vida "primitivo" (com o perdão da expressão) não podia ser compreendido pelo Antropólogo, nos "termos de sua própria cultura" - para citar Geertz. Eventualmente, para ser compreendido, seu trabalho poderia ser "descriptografado" para o código de sua cultura "civilizada", perdendo, entretanto, o teor original; ou ainda tal trabalho resultaria inútil se digamos - fosse direcionado ao conhecimento popular da sociedade estudada, dentro da qual um trabalho "científico" não tem nenhum sentido: nos termos daquela cultura.

Essa postura advogada por Geertz não se distancia muito dos desafios enfrentados pelo historiador, pois ele também busca traduzir os significados de uma "sociedade estrangeira", nos termos de sua própria sociedade - embora o grau de "estranhamento" experimentado pelo antropólogo, deva ser um pouco maior. Nesse caso, a fronteira que separa sua sociedade (do historiador) da sociedade-outra, é o tempo.

Por outro lado, a compreensão - necessária para esse olhar mais aguçado - não exclui a explanação do olhar "macro-abstrato"; justamente porque são dois olhares distintos e não simplesmente um olhar "de perto" e outro "de longe", para o mesmo quadro. Deste modo, não devemos nos reportar a um Contexto-Macro para entendermos a essência, para entendermos a razão última de uma realidade espacialmente reduzida. É verdade que o Macro reverbera sim, no Micro, porém certas "camadas" da realidade são pontualmente situadas e, para usar uma noção da Termodinâmica: não precisam importar energia para continuar funcionando.

É possível, assim, falarmos de autonomia do Micro (o Campo das Ciências Sociais) na sua relação com o contexto, em consequência das suas próprias circunstâncias; e de suas próprias regras:

${ }^{9}$ Essa cientificidade é, ela mesma, um aspecto da chamada "cultura ocidental" e não um traço metacultural alcançado arduamente no ocidente, ao cabo de algum processo evolutivo. Enfim, traço metacultural esse capaz de olhar de fora (objetivamente) as "culturas", como se elas fossem cegas.

Oficina do Historiador, Porto Alegre, EDIPUCRS, v. 7, n. 1, jan./jun. 2014, p. 121-137. 
O princípio do movimento perpétuo que agita o campo não reside num qualquer primeiro motor imóvel - o Rei-sol neste caso - mas sim da própria luta que, [...] reproduz as estruturas e as hierarquias deste. Ele reside [o motor] nas ações e nas reações dos agentes que, a menos que se excluam do jogo e caiam no nada, não têm outra escolha a não ser lutar para manterem ou melhorarem a sua posição no campo [...]. (BOURDIEU, 1998, p. 85)

Daí o caráter antropológico dessa abordagem escalar, ou seja, a necessidade de nos despirmos de convicções, de apriorismos teóricos, de conhecimentos prévios - as regularidades, por exemplo - e olharmos o detalhe, compreendendo (principalmente) seu funcionamento; além, é claro, compreendendo seu sentido.

Exemplificando enfim essa autonomia do Micro, recordemos que Le Roy Ladurie (1981) descreveu aquela sua "vila occitânica", tal qual um legítimo antropólogo e destacou a coexistência (relativamente harmônica, até o "trauma da Inquisição") dos poderes locais com os poderes gerais do rei francês - para não dizer, anacronicamente, "nacionais". Nota-se, ao longo das seiscentas páginas do livro, que a presença do Senhorio e (a fortiori) da Vassalagem é praticamente nula. Além do que, como que em acordo com Ginzburg, Ladurie escolhe o nome próprio como instrumento para organizar a narrativa e, nesse aspecto, brilham as estrelas de primeira grandeza de Pierre Clergue e Béatrice de Planissoles. A forma como essa mulher, filha de um cavaleiro, é estuprada sem que isso viesse a se constituir num trauma; o adultério que ela pratica juntamente com o cura (P. Clergue), enquanto teme pela reação de seu marido; e finalmente, como ela, de idade avançada, se apaixona por um jovem e pode enfim dar vazão a sentimentos mais "contextualizados" - é importante lembrar que o "amor romântico" é uma expressão típica daquele tempo e região: o Languedócio trovadoresco -, são circunstâncias muito específicas que devemos ter em consideração para entendermos "realmente" o que se passou naquela vila (Montaillou), naquele tempo (virada do século XIII para o XIV).

Reside aí a importância de se compreender o funcionamento do Campo, posto que é onde (na Escala em que) a Micro-História se efetiva. Para concluir o raciocínio com uma metáfora (da relação entre Macro e Micro):

[...] Sem o patrão/ As paredes cairiam e as máquinas encher-se-iam de ferrugem./ Se algures fizessem um arado/ Ele nunca chegaria ao campo sem/ As palavras avisadas do industrial aos camponeses: quem,/ De outro modo, poderia falar-lhes na existência de arados? E que/ Seria da propriedade rural sem o

Oficina do Historiador, Porto Alegre, EDIPUCRS, v. 7, n. 1, jan./jun. 2014, p. 121-137. 127 
proprietário rural?/ Não há dúvida nenhuma que se semearia centeio onde já havia batatas. (BRECHT, 2000, p. 32)

\section{Fonte de problema}

Mesmo com a convulsão sofrida por Montaillou, em decorrência do processo da Inquisição - esse "cavalo de Átila” montado pelo bispo Fournier -, a constância das práticas e valores perdurou como pano de fundo frente o qual as "anedotas inúteis"10 se substituíam continuamente. Um pano pro-fundo, além de longo e lento.

A diáspora que se seguiu às primeiras prisões apenas provava que a vida continuaria seu curso; nem que fosse ao menos para os montalhoneses que ardilosamente escaparam do apetite implacável do papado - no momento mesmo em que, como o gigante Polifemo, a Inquisição teria ficado entre o bando de Odisseu e a única saída da caverna onde os marinheiros foram sendo mortos. Por outro lado, todos os habitantes varões da vila, e as moças que tinham menos de 12 anos de idade (LE ROY LADURIE, 1981, p. 98), foram alijados da perseguição: “[...] Em 1308, Geoffroy d'Ablis, inquisidor de Carcasona, arresta, en la aldea de Montaillou, a toda la población, excepto los niños.” (Idem, p. 18)

E esses fugitivos "sempre" olharam para trás - sem maiores riscos; ao contrário dos outros, que fugiram de Sodoma. O ostal ("lar") continuou sendo a unidade principal de sociabilidade e a linhagem, como atestam as lágrimas de Pierre Maury - lágrimas, de condolência perante a recusa de hospitalidade na casa de parentes $^{11}$ - ainda fornecia o cimento para os agregados humanos que perduravam em Montaillou; mais renitentemente do que as próprias rochas pirenaicas.

\footnotetext{
${ }^{10}$ Aquilo que, na definição de Comte, constituía o objeto de estudos dos historiadores em sua época. Motivo pelo qual ele advogava a premência de uma "história sem nomes". (BURKE, 1991)

11 “[...] Vete: por tu culpa, podría venirles desgracia a todos los amigos - declara en pleno Montaillou Guillaume Belot a Pierre Maury, de parte de Arnaud Fauré, que, sin embargo, es tío del buen pastor. Pierre Maury estalla en sollozos cuando oye esta última frase; ha compreendido que, por miedo a la Inquisición, los Belot y los Fauré, que, sin embargo, son sus convecinos y parientes, le han tachado del número de sus amigos: le rehúsan, por tanto, la prestación sagrada de hospitalidad [...]”. (LE ROY LADURIE, 1981, p. 180)
}

Oficina do Historiador, Porto Alegre, EDIPUCRS, v. 7, n. 1, jan./jun. 2014, p. 121-137. 
Mas, qual é a lição dessas "rochas humanas"? O que Ladurie pode nos ensinar com essa etnografia quase mineral? Bem. Uma questão inicial é respondida no âmbito da própria Antropologia. Uma vez que ela, tendo se distanciado nas últimas décadas das populações tradicionalmente estudadas (por "pilares" como Alfred Kroeber, Franz Boas e o próprio Malinowski) não deve permitir que se oculte o postulado categórico segundo o qual o ponto de vista estrutural (no sentido da recepção historiográfica do termo e não no sentido "levistraussiano") é um privilégio epistemológico dessa mesma ciência. Mais do que isso: a "duração", nos estudos clássicos da Antropologia, era "estruturalmente" longa - não é outra a ideia que repousa por trás do polêmico termo, "pré-história". Esse "estrutural antropológico" repito: no sentido em que o historiador consagrou a dicotomia estrutura/conjuntura e que Thompson (1981), entre outros, utiliza; inclusive numa famosa crítica a um "estruturalista" na acepção não historiográfica do termo - enfim, é principalmente na tradição antropológica de língua inglesa, na qual o conceito de Pattern é forjado, que os estudos sobre permanência suplantam, em muito, os estudos sobre mudança:

[...] a conduta padronizada e as respostas aceitas, aprendidas tão bem que provocam reações automáticas aos estímulos aprovados da cultura por parte de cada membro de uma sociedade, constitui a matéria-prima da qual se fazem as formas estruturadas $^{\mathbf{1 2}}$. (HERSKOVITS, 1963, p. 240, grifo nosso)

É dessa forma que Ladurie coloca o problema. Apesar de realizada uma Micro-análise, o Campo - onde as relações entre sujeitos produzem as estruturas e não o contrário - é menos importante que a paisagem, na qual as casas (por exemplo) aderem ao relevo mimeticamente; e os animais dormem sob o mesmo teto que as pessoas: "Según este texto, hombres y cerdos hacen, por tanto, casa común [...]" (LE ROY LADURIE, 1981, p. 71). Paisagem esta, onde a monotonia imemorial dos ciclos naturais: dias-noites, verões-invernos, partos-enterros, é a medida de um mundo que se apresenta como imóvel; ou, confrontados (os habitantes da paisagem) com a notícia do advento do Anticristo e do "final dos tempos", a certeza de que o mundo "no tiene comienzo ni fin" (RANCIÈRE, 1993, p. 90) - “[...] esos hombres de las montañas que viven alejados de los dogmas rigurosos y de las ideas cambiantes de las ciudades [...].” (Ibidem, p. 91)

${ }^{12}$ Leia-se: "Cultural Patterns".

Oficina do Historiador, Porto Alegre, EDIPUCRS, v. 7, n. 1, jan.jjun. 2014, p. 121-137. 
O problema é que, diante do descontínuo e do efêmero que, mal crispa o cenho na presença do fato inédito e já se desfaz, lançar mão do mesmo procedimento se mostraria equivocado. O Zé Coimbra (1915/1985), da minha pesquisa ${ }^{13}$, não serve como índice de regularidades. Ele não é bom um exemplo, daquilo que em Sociologia, denomina-se "socialização"; mas antes, daquilo que os Antropólogos consagraram com o termo "desvio":

Em geral, todos os indivíduos que ocupam dada posição na estrutura de uma sociedade particular reagirão a muitas situações bastantemente do mesmo modo. Que qualquer indivíduo de tal grupo manifeste essa reação nada prova a respeito de sua personalidade, exceto que tem capacidade normal de aprender. Suas predisposições pessoais revelar-se-ão não pelas suas reações culturalmente padronizadas, mas pelos seus desvios do padrão cultural. (LINTON, 1967, p. 37)

O que não significa que um abismo ontológico separe esta personagem (Zé Coimbra) daquele Pierre Maury (1282-83/1324?), pastor nos Pireneus, generoso amigo e cátaro por menosprezo ao luxo católico mais do que por inclinações teológicas abstratas. A parte o fato muito significativo, aliás - de que profundas revoluções sociais desenrolaram-se em torno do ciclo de vida dessa minha personagem, num contraste evidente com a existência atribulada de P. Maury, mas ainda assim imersa na mais densa imobilidade montano-camponesa, enfim, de lado essa circunstância, percebo diversas analogias entre os valores e as práticas de Coimbra e Maury. Anacronismo? Certamente! Dizer que o mesmo gesto tem conteúdos diferentes no sul de Minas Gerais ou no oeste da Occitânia é tão trivial na Historiografia ${ }^{14}$ que repeti-lo, seria para mim, motivo de justo menosprezo por parte dos historiadores. Porém, a água-forte que a personalidade desses dois sujeitos imprime em meu julgamento não pode ser explicada a partir da diferença entre os contextos, ou a fortiori entre as Estruturas Sociais - "plásticas" e "rígidas", sucessivamente em Minas Gerais e Occitânia -, mas sim a partir da mesma concepção teórica de Tempo Histórico.

Se nos determos e atentamente olharmos para Pierre Maury como o fiel amigo de Bélibaste - sendo que esse parfait ${ }^{15}$, muito longe de qualquer perfeição, nunca demonstrou

\footnotetext{
${ }^{13}$ Zé Ninguém: trajetórias de um comunista no interior de São Paulo (1945/1985).

${ }^{14}$ A história é a ciência das diferenças e não das analogias (VEYNE, 1983, p. 40). Nesse sentido, imagino que "minha origem" geográfica acaba interferindo na maneira como raciocino.

15 Entre os cátaros, uma distinção estabelecida em sacramento, erigia à condição de "guia" (equivalente à de sacerdote), alguns dos seus "crentes" (sectários). Esses "guias" eram denominados: perfeitos.
}

Oficina do Historiador, Porto Alegre, EDIPUCRS, v. 7, n. 1, jan./jun. 2014, p. 121-137. 
reciprocidade - e também como raptor de sua irmã Guillemette (LE ROY LADURIE, 1981, p. 131-132) - livrando-a de um violento marido, o qual nem mesmo a visita do cunhado impediu de “exercer" seu poder marital; numa sociedade androcêntrica -, só então aquela impressão de continuidade (e coerência), entre normas e práticas, que encaixava no grande "puzzle social" a ínfima peça (esse Pierre), começa a se desvanecer. A descrição que Ladurie (1981) nos oferece é bem restritiva - a natureza das fontes: "autos do processo inquisitorial", assim lhe impõe. Mas, assim mesmo, sabemos que Pierre:

- associa-se aos hereges tranquilamente;

- participa de seus banquetes entre os comensais;

- escapa da perseguição inquisitorial, não apenas uma vez, com o auxilio de algum compadre "infiltrado" no próprio sistema;

- troca de "patrão" em várias ocasiões, assim como de localidade;

- amealha, seguidas vezes, poupanças e depois as perde;

- casa-se com Raymonde porque Guillaume Bélibaste, infringindo a norma de seu "sacerdócio", engravidara a moça e separa-se dela ao simples pedido do mesmo Bélibaste, seu amigo (Ibidem, p. 142-143);

- e, finalmente, como Sócrates bebeu a cicuta, Pierre Maury se deixa apanhar, pela Inquisição ${ }^{16}$ : “[...] Condenado a cárcel en 1324, desaparecerá desde entonces de nuestro horizonte de archivos." (Ibidem, p. 144).

Entre todas as ações, o que menos interessa é o exercício diário, por parte de Pierre, dos seus "automatismos aprendidos socialmente" - como não se banhar, por exemplo. Mas, suas "entregas" (aos amigos e aos inimigos) reluzem, na sombra das estruturas.

A concepção de Tempo implícita na descrição mais "voluntarista" de P. Maury é aquela da incerteza, na qual: "Cada seqüência é concebida como um nexus onde atuam vários desenvolvimentos possíveis" (GRIBAUDI, 1998, p. 139). Ao passo que a concepção de Tempo que reside por trás da repetição cega, da confirmação da regra, da continuidade, é aquela da

\footnotetext{
${ }^{16}$ Aliás, se “deixou apanhar" como Menocchio (GINZBURG, 2006, p. 159): “E assim deixava-se ficar ali, esperando pelos seus perseguidores." O que nos faz pensar se Menocchio e Maury tinham, realmente, meios de escapar ou se, por outro lado, a certeza da punição se prefigurava, realmente, na cabeça de ambos.
}

Oficina do Historiador, Porto Alegre, EDIPUCRS, v. 7, n. 1, jan./jun. 2014, p. 121-137. 
identidade entre fenômeno e categoria, onde "[...] as diferentes formas destacadas são assumidas e interpretadas como a expressão imediata de leis estruturais que caracterizariam a evolução histórica e a determinariam como necessária.” (Ibidem, p. 158)

Ora. As fontes nos informam sobre o ocorrido, mas elas, igualmente, apontam para as virtualidades do ucrônico - os acontecimentos que nunca resultaram em "atualidades" (PORTELLI, 1993, p. 50): Maury "poderia" ter continuado casado com Raymonde e eles "poderiam" ter vivido o resto de suas vidas na Catalunha. Mas, se ele decidisse não se separar dela, haveria a necessidade de que ela também concordasse em continuar aquele matrimônio, pois a "teia social" que a Micro-análise nos autoriza descrever é interativa; e não "monológica". Além disso, as circunstâncias que "concorrem" na atualização das virtualidades são fortemente condicionantes (embora não sejam "absolutamente" condicionantes). Por exemplo, a rede social constituída pelos parentescos e pelos compadrios de Maury não se estendia ad infinitum e, portanto, não poderia auxiliá-lo (contra a Inquisição) em qualquer lugar ou a qualquer tempo em última instância, Jacques Fournier, talvez até por "carreirismo", se mostrara incorruptível quando da prisão do cura Pierre Clergue (LE ROY LADURIE, 1981, p. 103); circunstância em si mesma coatora.

De Montaillou para São Sebastião do Paraíso, vemos Zé Coimbra riscando com carvão a parede da sua casa (SOUZA NETO, 2012), antes de aprender, aproximadamente em 1950 e em São José do Rio Preto, com José Antônio - o "Da Silva” - a confeccionar telas e pintá-las. Telas as quais o levariam à Flórida-USA e à Cidade do México (DEPART. EDUCAÇÃO E CULTURA, 1992-1993). O mesmo matuto que, adolescente, tirava a sesta com o chapéu por travesseiro, para se levantar prontamente ao primeiro grito de seu pai (SANTOS, 2012).

Sua biografia, plena de eventos comuns: casamento, nascimento e morte dos filhos, emprego e casa própria, que o enquadram na monotonia extrema das médias: Família Média da Transição Demográfica, Salário Médio das Classes Trabalhadoras, etc.; essa biografia, enfim, esconde seus próprios tesouros. Comunista que era - além de artista plástico relativamente reconhecido - Zé Coimbra manteve contatos duradouros com notórios ícones do comunismo brasileiro: Luis Carlos Prestes - o qual entrevistou em $1984^{17}$ - é um exemplo. Ao lado disso ele era profundamente espiritualizado - não obstante o fato de que o marxismo ortodoxo repudia a

\footnotetext{
${ }^{17}$ Entrevista transcrita e publicada (pelo jornalista Silas Nogueira) no Suplemento do Jornal da U.M.U. de 1984 (de Mococa-SP), na chamada do qual se lê: "Falta um Partido Revolucionário!"
}

Oficina do Historiador, Porto Alegre, EDIPUCRS, v. 7, n. 1, jan./jun. 2014, p. 121-137. 
religião e outras formas de "pensamento mágico". Mas, mesmo sua espiritualidade não era uma repetição de dogmas cristãos (por exemplo), onde o mundo está apartado irremediavelmente de Deus, desde o Pecado Original e os homens devem "sofrer seu trabalho" para tirar dele o pão. Zé Coimbra não dividia a realidade entre: matéria de um lado, e espírito de outro: "R.P: Esse envolvimento é uma forma de dizer que a Arte é uma maneira de se relacionar com o sobrenatural? José Coimbra: Mas o que é sobrenatural? Tudo é natural." (COIMBRA SOBRINHO, 1983, s/p).

Indissociabilidade que, quer me parecer, ecoa numa certa idéia de Destino; tal qual a compartilhada por P. Maury, P. Clergue e outros montalhoneses. O Destino pagão que, mais do que a ingerência de um Deus-monarca na vida dos crentes-súditos, indica uma contiguidade entre o homem e a terra (espírito e matéria). Ideia explicitada pelo aforismo que Fournier ouviu da boca de um pastor: "el alma del hombre es de pan" (LE ROY LADURIE, 1981, p. 187); e ideia inclusive oposta àquela outra segundo a qual o corpo e não a alma, é que é pão; é pão e terra (o pó). “[...] o Senhor Jesus, na noite em que foi traído, tomou o pão; E, tendo dado graças, o partiu e disse: Tomai, comei; isto é o meu corpo que é partido por vós; [...]”.(BÍBLIA SAGRADA, 1Cor 11, 23-24)

Da mesma forma, o trabalho, na visão de Zé Coimbra era um gesto criador. Esse sujeito que (de uma cidade a outra) nunca conseguiu se desvencilhar do solo: "Se eu ficar sem pintar acho que não vivo não. Agora, tem uma coisa... se eu viver no campo, plantando, mexendo com horta, eu acho que a pintura não faz tanta falta" (COIMBRA SOBRINHO, 1983, s/p); e quando o que havia sob os pés era cimento e asfalto, ele retratou em suas mais de 100 telas pintadas a óleo, sobretudo a terra arada, as plantações e os lavradores "criando o mundo". Lavradores que viveram ainda, muito depois do êxodo, em seu imaginário.

\section{Conclusão}

A biografia que assim mostra um sujeito - Zé Coimbra - como nuance, uma nuance tanto do comunismo, como do migrante, do pai de família, trabalhador etc., é a mesma capaz de fornecer material para uma generalização que confirme a validade de normas ou tendências. Esse 
é outro ponto de vista e tem suas qualidades. Porém, somente a partir da Micro-análise essa narrativa (grafia) adquire vida (bio). É vista de perto que a trajetória desse migrante comunista, assim como a transumância daquele pastor medieval (Maury), adquire sentido e, porque não dizer, fornece sentido à própria "biograficidade" - o conteúdo, compulsório, de todo e qualquer nome próprio: José, Pierre, Elias etc.

É importante ressaltar também que, numa Micro-análise, as noções de "normal" e "desviante" perdem sua significação, pois a construção metodológica da norma visa estabelecer médias entre temas e não entre biografias completas. O pesquisador extrai, artificiosamente, da realidade, um seguimento que the interessa conhecer estaticamente; por exemplo, quantas pessoas em Montaillou banham-se com freqüência. A regra diz que a maioria nunca se banha e o comportamento desviante estabelece que esse ou aquele morador "banha-se" - digamos diariamente. Ora. Se o desviante banha-se diariamente isso não faz dele uma pessoa desviante, pois se em todos os outros "temas" essa pessoa se comportar ordinariamente, o fato de que ela talvez por alguma neurose - se banhe todos os dias, não explica nada acerca de sua sociabilidade, a não ser que seu cheiro possa - digamos - desagradar à maioria. De qualquer forma, Pierre Maury e Zé Coimbra não se apresentam assim, tão excepcionais; mesmo quando tomados microanaliticamente. Mas, é curioso notar que a Escala - ao menos na Geografia contemporânea sempre permite uma apropriação do Real, nessa operação mutilatória dos "temas estatísticos", pois muitas vezes nos debruçamos sobre grupos de fragmentos, ao invés de estudarmos as "pequenas totalidades".

Enfim, há mais sobre Escalas e que evitei discutir em função dos objetivos. Por exemplo, a forma como as Micro-escalas se organizam em conjuntos: que não são, necessariamente a Macro-escala. Brenner (2001) utiliza a expressão "aninhamento" ao se referir à nossa percepção da Escala como uma totalidade composta por planos hierarquizados: "Processes of scalar structuration do not produce a single nested scalar hierarchy, an absolute pyramid of neatly interlocking scales [...]" (p. 606). Como as pessoas têm uma percepção unitária de mundo, o aninhamento vai resultar da "forma" como elas realizam a síntese. Quais elementos poderiam interferir no modus operandi, desse trabalho de síntese, é uma pergunta viável. Talvez haja ainda pretextos para o historiador voltar a dialogar com o geógrafo, como no tempo de Braudel.

Oficina do Historiador, Porto Alegre, EDIPUCRS, v. 7, n. 1, jan./jun. 2014, p. 121-137. 


\section{REFERÊNCIAS BIBLIOGRÁFICAS}

BATALHA, C. H. M. Escrevendo a biografia dos obscuros e ativos: a experiência do dicionário do movimento operário na cidade do Rio de Janeiro. Revista Perseu, n. 3, ano 3, São Paulo, maio 2009. Pp. 173-183.

BOURDIEU, P. O poder simbólico. Trad. Fernando Tomaz. 2. ed. Rio de Janeiro: Bertrand Brasil, 1998.

BRECHT, B. Dificuldade de governar. Trad. Arnaldo Saraiva. Quinzena, n. 293. São Paulo, CPV, out. 2000. P. 32.

BRENNER, N. The limits to scale? Methodological reflections on scalar structuration. Progress in Human Geography, n. 25, 4, Manchester-UK, 2001. Pp. 591-614.

BURKE, P. O Antigo Regime na Historiografia e seus críticos. In: BURKE, P. A Revolução Francesa da historiografia: a Escola dos Annales (1929-1989). Trad. Nilo Odália. São Paulo, Editora UNESP, 1991.

CABRAL, J. P. "Aromas de urze e de lama": reflexões sobre o gesto etnográfico. Revista Etnográfica, n. 11, Lisboa, maio 2007. Pp. 191-212.

GEERTZ, C. "Do ponto de vista dos nativos": a natureza do entendimento antropológico. In: $O$ saber local - novos ensaios em antropologia interpretativa. Petrópolis: Vozes, 1998.

GINZBURG, C. O queijo e os vermes: o cotidiano e as ideias de um moleiro perseguido pela Inquisição. Trad. Maria Betânia Amoroso. São Paulo: Companhia das Letras, 2006.

GRIBAUDI, M. Escala, pertinência, configuração. In: REVEL, J. (Org.) Jogos de escala. Trad. Dora Rocha. Rio de Janeiro: Editora FGV, 1998.

HERSKOVITS, M. J. Antropologia cultural: man and his works. Trad. Maria José de Carvalho e Hélio Bichels. Tomo I. São Paulo: Mestre Jou, 1963.

HOBSBAWM, E. A era dos impérios. Trad. Sieni Maria Campos e Yolanda Steidel de Toledo. 8. ed. Rio de Janeiro: Paz e Terra, 2003.

LE ROY LADURIE, E. Montaillou: aldea occitana, de 1294 a 1324. Versión castellana de Mauro Armiño. Taurus Ediciones, Madrid, 1981

LENCIONI, S. Concentração e centralização das atividades urbanas: uma perspectiva multiescalar. Reflexões a partir do caso de São Paulo. Revista de geografía norte grande, n. 39, Santiago-CHI, 2008. Pp. 07-20. 
LINTON, R. Cultura e personalidade. Trad. Oscar Mendes. São Paulo: Mestre Jou, 1967.

PORTELLI, A. Sonhos Ucrônicos. Memórias e possíveis mundos dos trabalhadores. Trad. Maria Therezinha Janine Ribeiro. Projeto História: revista do PEPGH do departamento de história da PUC. São Paulo, n. 10, dez. 93. Pp. 41-59.

RANCIÈRE, J. Los nombres de la historia: una poética del saber. Trad. Viviana Claudia Ackerman. Buenos Aires: Ediciones Nueva Visión, 1993.

REVEL, J. Microanálise e construção social. In: REVEL, J. (Org.) Jogos de escala. Trad. Dora Rocha. Rio de Janeiro: Editora FGV, 1998.

. Micro-história, macro-história: o que as variações de escala ajudam a pensar em um mundo globalizado. Revista Brasileira de Educação, v. 15, n. 45, Rio de Janeiro, set./dez. 2010. Pp. 434-444.

RIBEIRO, J. C.; GONÇALVEZ, M. A. Região: uma busca conceitual pelo viés da contextualização histórico-espacial da sociedade. Revista Terra Livre, ano 1, n. 17, São Paulo, 2001. Pp. 79-99.

THOMPSON, E. P. A miséria da teoria ou um planetário de erros: uma crítica ao pensamento de Althusser. Trad. Waltensir Dutra. Rio de Janeiro: Zahar, 1981.

VEYNE, P. O inventário das diferenças. Trad. Sônia Saizstein. São Paulo: Brasiliense:1983. 


\section{FONTES}

COIMBRA SOBRINHO, J. "A arte é uma luz em tudo isso": depoimento [abril de 1983] Mococa: O Repórter do Povo. Entrevista concedida a Silas Nogueira.

DEPARTAMENTO DE EDUCAÇÃO E CULTURA DA PREFEITURA MUNICIPAL DE MOCOCA. Exposição vida e obra de Zé Coimbra [encarte], museu de artes plásticas "Quirino da Silva". Mococa-SP, dez.1992/ jan.1993.

SANTOS, L. M. S. Entrevista com Lurdes Maria de Souza, sobrinha de José Coimbra: depoimento. [30 de setembro de 2012]. Entrevista concedida a Elias Coimbra da Silva.

SOUZA NETO, J. Entrevista com João de Souza, irmão de José Coimbra: depoimento. [23 de setembro de 2012]. Entrevista concedida a Elias Coimbra da Silva.

ARTIGO ENVIADO PARA PUBLICAÇÃO EM: 15.09.2013

ACEITO PARA PUBLICAÇÃO EM: 08.02.2014 